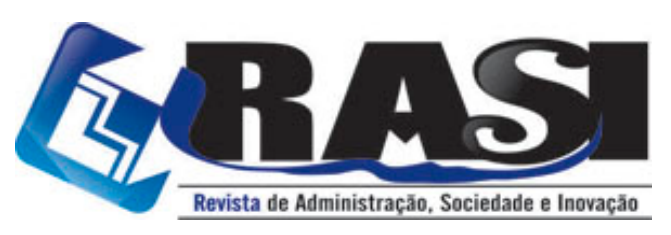

http://www.rasi.vr.uff.br

RASI, Volta Redonda/RJ, v. 7, n. 1, pp. 124-139, Jan./Abr. 2021

\title{
Os Primeiros Impactos da Indústria 4.0 sobre o Setor de Papel e Celulose
}

\author{
Sarah Cristina Ribeiro Ferreira (UFU) - sarahcristina_rf@hotmail.com
}

Germano Mendes de Paula (UFU) - germano@ufu.br

\begin{abstract}
Resumo:
O objetivo deste artigo é analisar os impactos da Indústria 4.0 no setor de papel e celulose. A metodologia aplicada consiste na identificação dos efeitos de oito clusters tecnológicos (produção inteligente e conectada, inteligência artificial, tecnologias de redes, biotecnologia e bioprocessos, nanotecnologia, materiais avançados e armazenamento de energia) sobre o setor, a partir da aplicação de questionários para a identificação da influência dessas inovações sobre a realidade mundial e brasileira. Os resultados apresentados demonstram a difusão e importância atribuídas a essas tecnologias no setor em 2017, em 2022 e em 2027.
\end{abstract}

Palavras-Chave: Indústria 4.0; Papel e Celulose; Inovação.

\section{The Firsts Impacts of Industry 4.0 on the Pulp and Paper Sector}

\begin{abstract}
:
The purpose of this paper is to analyze the impacts of Industry 4.0 on the pulp and paper sector. The applied methodology consists in the identification of eight technological clusters (internet of things, internet of things, intelligent and connected production, artificial intelligence, networking technologies, biotechnology and bioprocesses, nanotechnology, advanced materials and energy storage) and their first effects on the industry. From the application of questionnaires to identify the influence of these innovations on the world and Brazilian reality. The results demonstrate the diffusion and importance attributed to these technologies in the sector in 2017, in 2022 and in 2027.
\end{abstract}

Keywords: Industry 4.0; Pulp and Paper; Innovation.

\begin{tabular}{c}
\hline $\begin{array}{c}\text { Universidade } \\
\text { Federal } \\
\text { Fluminense }\end{array}$ \\
R. Desembargador Ellis Hermydio Figueira, 783, Bloco A, sl. 218, Aterrado. \\
$27213-415$ - Volta Redonda, RJ - Brasil \\
www.uff.br \\
\hline $\begin{array}{c}\text { Copyright (c) 2020 RASI. Todos os direitos, até mesmo de tradução, são reservados. É } \\
\text { permitido citar parte de artigos sem autorização prévia, desde que seja identificada a fonte. }\end{array}$ \\
\hline
\end{tabular}




\section{Os Primeiros Impactos da Indústria 4.0 sobre o setor de Papel e Celulose}

\section{Introdução}

A partir da primeira revolução industrial, houve a transição para um novo processo de produção baseado na mecanização, revolucionando a economia e a estrutura em que se organiza a sociedade. O segundo período de transformação introduziu a divisão do trabalho e permitiu o nascimento do consumo em massa, a terceira permitiu a automação por meio do uso de eletrônicos e tecnologia da informação (TI) a nível industrial (Gtai, 2014; Santos, et al., 2018).

O desenvolvimento tecnológico impulsionou a produtividade industrial, reduzindo custos de produção e fornecendo soluções para o relacionamento com fornecedores e clientes por meio de novos modelos de negócios (Santos et al., 2018). Diante de um cenário de maior complexidade, demanda-se uma nova lógica de organização industrial, apresentada por meio da Industria 4.0. Este termo refere-se às tecnologias e conceitos da organização de valor, baseado em fábricas inteligentes e modulares conectadas por sistemas ciberfísicos. A Indústria 4.0 cria e articula fábricas inteligentes em um novo sistema produtivo e de comercialização gerando diferentes modelos de negócios (Hermann, Pentek, \& Otto, 2015; Iedi, 2017).

A indústria de base florestal vivenciou as três fases anteriores da transformação industrial, a contar pela criação da energia a vapor até a elétrica, passando pela integração progressiva das tecnologias de automação e informação. Assim, acompanha as inovações próprias a Indústria 4.0 (Martin, 2017). Desta forma, esse artigo tem o objetivo de avaliar de que modo as tecnologias próprias a Indústria 4.0 influenciarão a indústria de papel e celulose mundial e nacional, adotando a hipótese de que a Indústria 4.0 tem um alto impacto para os modelos de negócios e difusão elevada no setor a nível mundial.

A metodologia aplicada nesse trabalho consiste na identificação dos efeitos de oito clusters tecnológicos sobre o setor, utilizando a classificação empregada pelo IEL (2017), sendo estes, internet das coisas, produção inteligente e conectada, inteligência artificial, tecnologias de redes, biotecnologia e bioprocessos, nanotecnologia, materiais avançados e armazenamento de energia. Dessa forma, foram aplicados questionários (Anexo I) em duas das principais empresas atuantes no setor de P\&C para a identificação do impacto que a Indústria 4.0 exerce na realidade brasileira por meio das tecnologias apresentadas. Assim, busca-se, por meio de dados primários e secundários, examinar a experiência e a percepção de empresas líderes da indústria em um setor altamente concentrado.

Para alcançar o objetivo apontado, este artigo será dividido em quatro seções, além desta sucinta introdução. A primeira aborda as novas tecnologias da Indústria 4.0, enquanto a segunda aborda como opera o sistema produtivo de Papel e Celulose (P\&C). Por sua vez, a terceira tem como objetivo examinar a maneira com que as tecnologias inerentes a Indústria 4.0 se aplicam ao setor de $\mathrm{P} \& \mathrm{C}$ e os primeiros impactos que essa revolução desperta no Mundo e no Brasil. A quarta e última seção sintetiza as principais considerações do artigo.

\section{A Indústria 4.0 e seus principais Clusters Tecnológicos}

A mudança tecnológica é caracterizada pelo lançamento ou aprimoramento de produtos, processos produtivos, métodos gerenciais ou uso de insumos e matérias-primas e podem ser diferenciadas pelo seu grau de inovação e pela extensão da mudança em relação ao que havia antes (Conceição, 2000). O tipo de mudança tecnológica que possui a maior capacidade de gerar transformações é a introdução de um novo paradigma técnico econômico 
que se dá na forma de revolução industrial. Essa inovação se dá a partir: a) da alteração da estrutura de custos; b) da percepção de oportunidades de inovação; e, c) do surgimento de novos modelos organizacionais (Perez, 2010). A Indústria 4.0 engloba as três características responsáveis pela definição de um paradigma técnico econômico.

A Indústria 4.0 promove a melhora dos resultados pelo aumento das receitas e redução dos custos, promovendo uma melhora da eficiência global. A receita adicional é resultado do aumento de participação de mercado dos principais produtores, maiores margens em produtos e serviços, obtidas a partir da análise de dados, criação de novos produtos, serviços e soluções digitais, além do surgimento de produtos personalizados. Os menores custos e maior eficiência são resultado do controle de qualidade em tempo real, digitalização e automatização de processos, planejamento em tempo real para otimização da execução, produção flexível, utilização inteligente dos recursos humanos e maior velocidade nas operações (Martins, 2018).

O desenvolvimento da internet, de sensores e softwares e hardwares proporcionou a interoperabilidade dos sistemas, a virtualização, a descentralização dos controles dos processos produtivos, a adaptação da produção em tempo real e a flexibilização da produção alterarão o modelo organizacional de forma que haverá uma tendência à produção em massa de produtos altamente personalizados (Peixoto, \& Pereira, 2018).

Além disso, a Indústria 4.0 é caracterizada pela produção conectada por sistemas ciberfísicos a partir da criação de redes inteligentes e independentes capazes de interagir com processos reais e virtuais. Além disso, representa uma mudança de paradigma em que a produção se torna "descentralizada". Desta forma, há a integração dos processos verticalmente em toda a organização industrial, desde o desenvolvimento, a compra de insumos, a fabricação, logística, até a criação de novos produtos e serviços digitalizados, fornecendo soluções digitais personalizadas e serviços completos (Gtai, 2014; Santos, et al., 2018).

A Indústria 4.0 possui três características fundamentais: a) a digitalização e integração das cadeias de valor, desde o desenvolvimento do produto até a manufatura, logística e serviços, de forma que toda a informação sobre o processo se torna disponível em tempo real para todos os membros da cadeia de valor; b) a digitalização de produtos e serviços a partir da adição de sensores inteligentes ou da criação de novos produtos, permitindo que as empresas possam gerar dados para o aprimoramento dos produtos com o foco na necessidade dos clientes; c) a criação de modelos de negócios digitais, de forma que as firmas possam ampliar o acesso ao cliente, otimizando a interação da cadeia produtiva por meio de soluções digitais e personalizadas (PwC, 2016).

Ademais, a Indústria 4.0 também é caracterizada pela diferenciação das empresas no mundo dos negócios por meio da gestão de conhecimentos e capacitação dos seus funcionários (Schwab, 2016). Desta forma, o perfil e formação técnica dos empregados passa a ser um dos principais fatores para a adoção completa da Indústria 4.0. Além disso, o desenvolvimento de tecnologias que promovam soluções econômicas e compatíveis com as necessidades dos clientes, o compartilhamento do conhecimento, o desenvolvimento dos colaboradores e a modernização dos parques fabris configuram como os principais desafios para aplicação dessas novas tecnologias (Aires, Kempner-Moreira, \& Freire, 2017).

A aplicação dos sistemas tecnológicos próprios a Indústria 4.0 tem a capacidade de inovar infraestruturas fabris, produtos e processos produtivos, como resposta à crescente necessidade de flexibilidade e eficiência. A introdução de tecnologias inteligentes na 
produção afeta a tomada de decisão gerando maior autonomia e a integração de informações na tomada de decisão.

\subsection{Caracterização dos Clusters Tecnológicos}

A Indústria 4.0 possibilita a introdução de interfaces complexas na relação homem e máquina, detecção de fraudes, caracterização do perfil dos clientes e interação com a cadeia de valor em vários níveis. Segundo o IEL (2017), essa revolução pode ser compreendida por oito clusters tecnológicos que impactarão a indústria, constituindo-se por: a) Inteligência Artificial (IA), b) tecnologias de redes, c) Internet das Coisas (IoT, no acrônimo em inglês), d) Produção Inteligente e Conectada (PIC), e) materiais avançados, f) nanotecnologia, g) biotecnologia e bioprocessos e h) armazenamento de energia.

A IA está associada às tecnologias inspiradas no sistema nervoso humano e na maneira com o ser humano sente, aprende, raciocina e age. Assim, a partir de um conjunto sistematizado de conhecimentos, a IA pode ser aplicada à percepção, compreensão, processamento, interpretação, otimização e ação das máquinas. O big data e a computação em nuvem são tecnologias "instrumentais" utilizadas para o desenvolvimento da IA por meio da estruturação de grandes volumes de dados e seu armazenamento e processamento na nuvem. O objetivo final do avanço desse cluster é o desenvolvimento da capacidade de tomada de decisão das máquinas sem a intervenção humana direta (IEL, 2017; Freitas, 2017).

As tecnologias de rede são compreendidas pelo sistema de computadores, canais de transmissão e recursos relacionados e interligados com o objetivo de transporte de informações e a interligação de sistemas de distintos, mediante o uso de plataformas de automação de processos centralizadas e integradas (Santi, 2018). A IoT é definida pela interconexão de dispositivos informáticos incorporados em objetos cotidianos por meio da internet. Essa tecnologia é capaz de extrair e analisar dados para a tomada de decisão, alavancando o fluxo de informações industriais e sociais, revolucionando a comunicação empresarial e privada (Andrade, 2017).

PIC refere-se aos sistemas ciberfísicos de interconexão, digitalização, processamento e otimização da cadeia produtiva. Essa tecnologia proporciona o controle virtual do processo produtivo, que passa a ser feito remotamente, possibilitando que o processo se torne mais previsível por meio de processos de otimização, análise estatística, alertas sensoriais e modelagem preditiva (Martin, 2017). Há muita convergência entre as inovações de IoT, redes, IA e PIC, sendo a última compreendida como a mais abrangente e agregadora das demais (De Paula, 2018).

A biotecnologia é o conjunto de técnicas que utiliza organismos vivos, processos ou sistemas biológicos no meio industrial, por meio da combinação de engenharia genética, biologia celular e sistemas computacionais. Os clusters de nanotecnologia, materiais avançados e armazenamento de energia configuram como tecnologias derivadas da biotecnologia. A nanotecnologia é definida como a manipulação dos átomos para a produção de novos materiais em escala nanoscópica, ou seja, menor que $100 \mathrm{~nm}$ em pelo menos uma de suas dimensões (Florêncio, et al., 2017).

Materiais avançados representam avanços sobre materiais tradicionais, englobando materiais novos ou modificados com estrutura ou funcionalidade superior para sua aplicação comercial. Os materiais avançados permitem a introdução de novos mercados, bem como mudanças nos mercados já existentes (IEL, 2017). O Armazenamento de energia corresponde à utilização de reações químicas para estocar energia elétrica. Essas tecnologias são usadas para três fins principais: a) autonomia de sistemas em relação à rede de eletricidade, b) 
eletrificação de produtos e processos outrora dependentes de combustível fóssil e c) segurança das matrizes energéticas (IEL, 2017).

Segundo o IEL (2017), a difusão de novas tecnologias são afetadas por desafios socioeconômicos que exercem influência crítica no ritmo do desenvolvimento das inovações. Os principais desafios elencados são: a) ético ou regulatório, que dizem respeito às tecnologias que ameaçam valores éticos ou requerem medidas regulatórias; b) normativo, que estão relacionados à necessidade de estabelecimento de normas técnicas; c) tecnoeconômicos, que se referem às capacitações técnicas e organizacionais adaptadas a cada sistema produtivo; e, d) socioambientais, relacionam-se à percepção da sociedade sobre os riscos associados à produção ou ao uso das novas tecnologias.

Em todos os clusters há o potencial de inovações criadoras de novos mercados, o que reforça o potencial transformador dessas tecnologias. Por meio da adoção dessas tecnologias, os processos vêm se tornando cada vez mais complexos, adicionando valor à cadeia produtiva (IEL, 2017). Desta forma, a aplicação dos sistemas tecnológicos próprios a Indústria 4.0 tem a capacidade de inovar infraestruturas fabris, produtos e processos produtivos, como resposta à crescente necessidade de flexibilidade e eficiência.

\section{Observações sobre o Setor de Papel e Celulose}

A celulose é um composto natural existente nos vegetais, de onde é extraída, podendo ser encontrada em toda a extensão da planta. É um dos principais componentes das células vegetais e são frequentemente chamadas de "fibras", por sua forma alongada e pequeno diâmetro (Piotto, 2003). As fibras de celulose podem ser virgens, quando resultam diretamente do processo de transformação da madeira, ou recicladas, quando são obtidas de aparas de papel ou da reciclagem de papéis usados. Entretanto, a celulose reciclada não substitui por completo as fibras virgens, que se degradam nos vários ciclos reciclagem. A celulose é denominada integrada quando se destina à produção de papel em uma planta anexa à produção do insumo, ao passo que é denominada de mercado quando é comercializada como insumo para produção de papel (Biazus, Hora, \& Leite, 2010). Além disso, nem toda a produção é destinada à produção de papéis, como é o caso da celulose solúvel, destinada à fabricação de uma ampla gama de produtos, com destaque para a indústria têxtil (BNDES, 2012).

Segundo a classificação elaborada pelo BNDES (2012), a celulose, tanto de mercado quanto integrada, é agrupada em celulose kraft branqueada de fibra curta (bleached hardwood kraft pulp-BHKP) ou celulose kraft branqueada de fibra longa (bleached softwood kraft pulp - BSKP), celulose kraft não branqueada e pasta mecânica. A BHKP é produzida por meio de processo químico, suas principais aplicações são os papéis de imprimir e escrever (I\&E), sanitários, especiais, além de papel-cartão. É o principal tipo de celulose produzida no Brasil, totalizando $86,7 \%$ do total da indústria em 2018 (Ibá, 2020).

A maior parte da composição do papel é constituída a partir da celulose, que é o insumo mais importante no processo. Além desta, também são utilizadas matérias-primas não fibrosas, como cargas minerais, agentes de colagem, amidos e corantes (Piotto, 2003). Os papéis têm um amplo espectro de utilização e são classificados nas seguintes categorias: papel imprensa, papéis de imprimir e escrever (I\&E), embalagens e descartáveis. O papel imprensa é destinado majoritariamente à impressão de jornais, mas também inclui periódicos, revistas, listas telefônicas, suplementos e encartes. Papéis I\&E costumam ser divididos em quatro subgrupos dependendo de duas características, revestimento - revestidos ou não revestidos e fabricação - "wood free" se a composição for exclusivamente de celulose branqueada ou 
"wood containing" se na composição fibrosa houver pastas de alto rendimento além de celulose. Mencione-se que revestimento e a não utilização de pasta mecânica conferem maior qualidade e valor ao papel. A categoria de I\&E é muitas vezes agrupada com o papel imprensa sob a denominação de papéis gráficos. As embalagens incluem papéis kraftliner, testliner, sackraft, papel-cartão, entre outros.Os papéis descartáveis do tipo tissue ou higiênicos possuem finalidade sanitária, sendo seu principal produto o papel higiênico (BNDES, 2012).

$\mathrm{O}$ setor de $\mathrm{P} \& \mathrm{C}$ possui diferenças marcantes ao longo da cadeia produtiva. A indústria de celulose é globalizada e e se caracteriza por uma estrutura produtiva com tecnologia difundida e acessível, apesar da divisão entre fibra longa e fibra curta. Além disso, esse segmento do setor possui fortes barreiras à entrada: alto investimento, difícil acesso a terras e longo período de maturação do investimento. A indisponibilidade de terras e subutilização tecnológica podem inviabilizar um novo entrante. A competição é marcada por economias de escalas, movimentos de fusões e aquisições, acirramento da concorrência, poder de barganha com clientes, canais de distribuição e comportamento cíclico dos preços (Biazus, Hora, \& Leite, 2010; BNDES, 2012).

A indústria papeleira possui uma estrutura produtiva distinta em seus diversos segmentos, de forma que tais particularidades não permitem definir uma caracterização universal ao setor. Sendo que produtos padronizados de consumo generalizado, como papéis gráficos e embalagens, possuem escalas mínimas de eficiência elevadas em comparação com outros produtos do segmento (Pinho, \& Avellar, 2002; BNDES, 2012). A competição para os fabricantes de papel é definida pela localização das unidades fabris, sendo que estas são localizadas próximas aos consumidores. Segundo Hora, Ribeiro e Mendes (2018) os produtores localizados próximos a grandes mercados consumidores possuem maior competitividade em relação àqueles afastados de grandes centros.

A celulose é uma commodity, portanto seu preço é definido internacionalmente e possui uma alta sensibilidade às alterações da capacidade industrial, às mudanças de estoques, ao valor do dólar, aos custos de produção e transporte e à economia mundial, caracterizandose por um caráter cíclico (Biazus, Hora, \& Leite, 2010). Os preços de papel são derivados da celulose. A demanda de celulose está relacionada com o consumo de papel e este é sensível ao resultante do crescimento da população, da renda e do nível de escolaridade, de forma em que há uma relação direta entre esses indicadores e o consumo de papéis gráficos e tissue. Além disso, quão maior for produção industrial, maior será o fluxo de embalagens (Correa, 2014).

$\mathrm{A}$ indústria de $\mathrm{P} \& \mathrm{C}$ tem experimentado uma intensa transformação, na medida em que a demanda do setor tem aumentado nos últimos anos. No entanto, esse crescimento não se dá em todos os segmentos do setor, na medida em que há um decrescimento da demanda de papéis gráficos em mercados maduros. Entre 2000 e 2018, a produção global de papéis teve um crescimento de $1,3 \%$ ao ano em média. Nesse período, houve um decrescimento de $0,9 \%$ da produção de papéis gráficos e um crescimento de $3 \%$ de papéis tissue e $2,7 \%$ de embalagens. A celulose teve um crescimento médio de $0,3 \%$ nesse período, demonstrando o impacto da adoção em larga escala de fibras recicladas, na produção final de papéis (Fao, 2020). A figura 1 apresenta a produção de papéis, celulose e aparas de papel entre 2000 e 2018. 
Figura 1 - Produção mundial de celulose, papel e aparas de papel - 2000-2018

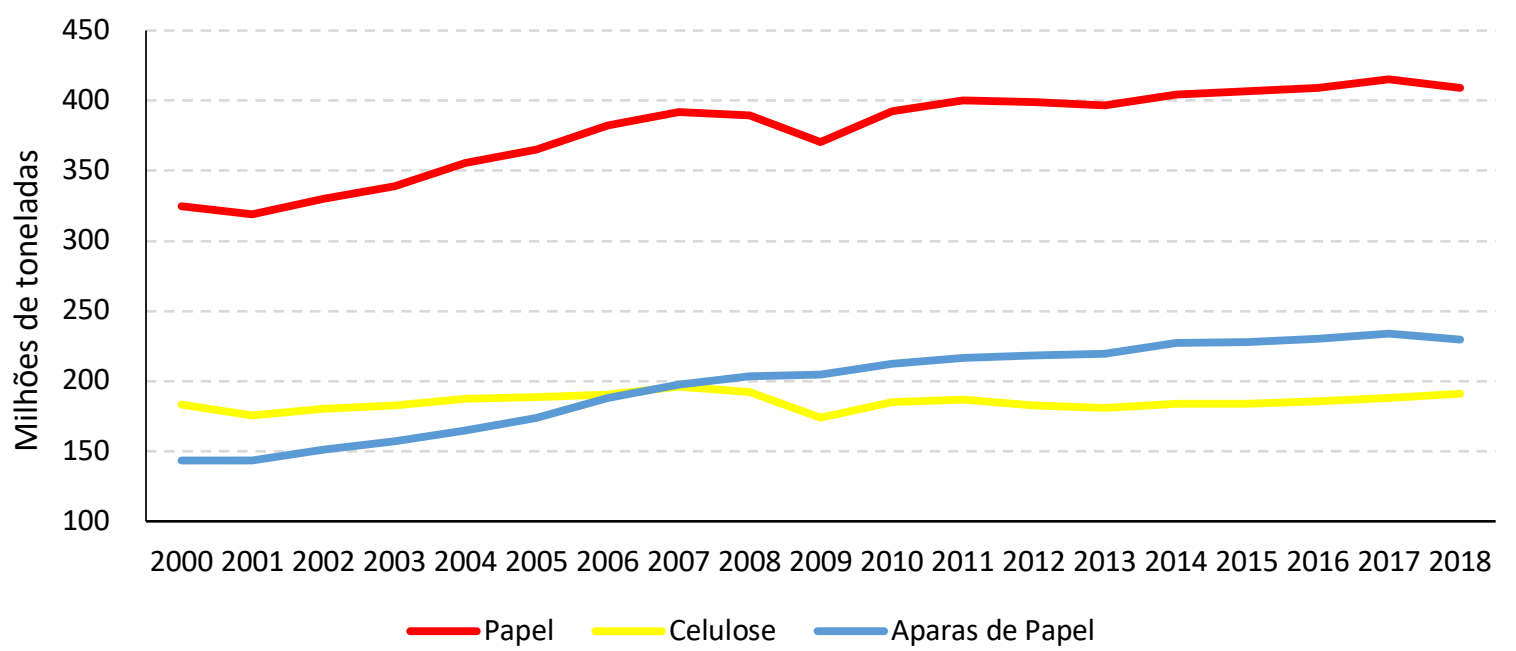

Fonte: Elaboração própria utilizando os dados da FAOSTAT (2020).

Segundo Berg e Lingqvist (2017), a demanda de produtos de P\&C tende ao crescimento na década de 2020, apoiado no aumento da demanda por embalagens, graças ao progresso do comércio eletrônico, e por papéis tissue dado o desenvolvimento de países emergentes que passam a desfrutar de melhores condições sanitárias.

Historicamente, a indústria de $\mathrm{P} \& \mathrm{C}$ acompanhou as tendências mundiais de globalização da cadeia produtiva industrial, ainda que dependendo de matérias-primas e mercados específicos.A tecnologia de fabricação de $\mathrm{P} \& \mathrm{C}$ evoluiu de forma incremental, sendo a principal alteração a introdução das máquinas no processo produtivo no início do século XIX. Desde então, a base tecnológica não passou por alterações drásticas embora tenha crescido em escala, portanto mudanças relativas à tecnologia são lentas para o setor (Ojala, Voutilainen, \& Lamberg, 2012). Ademais, nas atividades industriais o desenvolvimento de inovações incrementais pode ocorrer em curto prazo, enquanto na atividade de base florestal são necessárias décadas para o progresso de um novo processo ou produto. Os requerimentos quanto à escala de produção diferenciam-se ao longo da cadeia produtiva, bem como o grau de modernização fabril (De Paula, 2018).

O setor de P\&C é considerado de baixa-média intensidade tecnológica no âmbito global, dado sua baixa intensidade de pesquisa e desenvolvimento (P\&D), com média de investimento de 1,8\% da receita em P\&D na indústria mundial em 2011 (Laestadius,1998; OCDE, 2007; Galindo-Rueda, \& Verger 2016). A demanda, suprimento de fornecedores e o estágio da cadeia produtiva são fatores importantes para explicar o desenvolvimento tecnológico do setor, na medida em que alguns segmentos produtivos dependem de inovações prévias em outras indústrias, como na de bens de capital, ainda que o desenvolvimento de novos produtos seja uma estratégia interna (Ojala, et al., 2013; Hujala, et al., 2015).

O Brasil constitui um caso particular na indústria de $\mathrm{P} \& \mathrm{C}$. O país é o segundo maior produtor de fibra celulósica do mundo, produzindo 21,1 milhões de toneladas em 2018, o correspondente a $11 \%$ de toda a produção mundial. Essa alta parcela é derivada da alta competitividade do setor dadas as condições edafoclimáticas, o longo histórico em P\&D florestal e políticas industriais direcionadas ao setor. Além disso, O Brasil é o maior exportador de celulose do mundo, sendo $70 \%$ da produção brasileira voltada para mercados 
externos, de modo que $24 \%$ do total das exportações mundiais são brasileiras (Fao, 2020; Ibá, 2020).

Contudo, a competitividade brasileira não reflete para o segmento de papéis, em 2018 o país produziu 10,7 milhões de toneladas, o equivalente a $3 \%$ da produção mundial (Fao, 2020; Ibá, 2020). A diferença entre papel e celulose reside no fato de que a produção de papel brasileira é dominada por empresas de pequeno porte, além da concentração em torno de mercados consumidores, competição por recursos com a celulose, deficiências logísticas e a complexa carga tributária (BNDES, 2012).

\section{O Impacto da Indústria 4.0 sobre o setor de Papel e Celulose}

A Indústria 4.0 representa uma grande mudança para a indústria de P\&C. A forma de organização fabril tenderá a um sistema continuamente conectado, substituindo processos e funções individuais. As novas tecnologias tenderão a automatizar trabalhos repetitivos, de forma que o foco da atuação humana se torne a análise e tomada de decisões (Cepi, 2015). Haverá redução do contato entre homem e máquina, gerando maior segurança. As possibilidades de manutenção preditiva gerarão mais eficiência e, por consequência, maior tempo de vida útil dos ativos, bem como aumento da produtividade. A expectativa é que os dados baseados na experiência prévia de produção sejam acessíveis em toda a cadeia produtiva (Martin, 2017). As unidades fabris serão conectadas por sensores que serão utilizados para coleta, sincronização e visualização de dados. O registro de informações possibilitará que sistemas de processo se adaptem a diferentes estágios da produção. $\mathrm{O}$ processo de controle de qualidade permitirá a avaliação da produtividade de todo o sistema produtivo (Karlović, 2017).

A IoT permite o desenvolvimento da capacidade de capturar e compartilhar dados e informações do processo produtivo, a partir da conexão contínua e do uso de dados para tomada de decisão, diagnóstico de maquinário, direcionamento da produção e otimização de custos (Martin, 2017). Esse cluster tecnológico exige data centers eficazes para o estoque e processamento dos dados. As inciativas para o desenvolvimento dessa tecnologia de maneira sustentável são chamadas de Green IoT e possuem o objetivo de serem energeticamente sustentáveis e eficientes, além da redução da pegada de carbono relacionadas à IoT. Para o setor, o ciclo produtivo será focalizado em design, produção, utilização e descarte sustentável. De forma geral, a indústria de $\mathrm{P} \& \mathrm{C}$ tem se preocupado com a sustentabilidade, sendo os principais problemas identificados a eficiência energética, florestas sustentáveis, preservação da biodiversidade, gestão de recursos hídricos e reciclagem (Shaikh, Zeadally, \& Exposito, 2017; Jones, \& Comfort, 2017).

A automação de dispositivos de rede controlados por IA combinados com manipulação de dados por computação em nuvem tende a aumentar a produtividade e o valor adicionado da produção (Karlović, 2017). O bigdata permitirá a extração de informações para o controle do processo industrial, por meio de tecnologias de tomada de decisão em tempo real, como redes neurais artificiais, sensores virtuais e mineração de dados para a identificação de melhores cenários de produção (martin, 2017). O big data possibilitará o processamento e análise de grandes quantidades de dados, com maior eficácia do que métodos manuais.

A PIC tende a massificar o acesso às informações, facilitando tomada de decisões, de forma que as empresas possam oferecer suporte e entrega personalizados aos clientes. A virtualização e descentralização permitirão para a otimização das operações das plantas fabris, desde o tratamento de água e utilização de energia até o processamento de informações. As 
tecnologias de rede proporcionarão interconexão de sistema e uma maior gama de soluções, gerando uma grande quantidade de informações. Em vista de possíveis ataques cibernéticos, o setor de P\&C visa um projeto de segurança virtual com uso de tecnologia da informação (TI) e automação. Desta forma, os protocolos de segurança passam a ser dinâmicos, com avaliação de riscos presentes e indicação de melhorias em tempo real (Santi, 2018).

Biotecnologias de bioprocessos são fundamentais ao setor, na medida em que as unidades fabris são biorrefinarias, com grande conjunto de aplicações. $\mathrm{O}$ uso de novas enzimas cria novas possibilidades nos processos químicos da produção. As nanoestruturas indicam um grande número de possibilidades no setor, com destaque para a nanocelulose, que possui a possibilidade do desenvolvimento de novos produtos complementares a linha de produção atual (De Paula, 2018). Os materiais avançados representam uma transformação do uso de recursos da indústria de $\mathrm{P} \& \mathrm{C}$, cuja principal característica será a produção limpa, circular e ecológica. Além disso, na medida em que a celulose é um compósito com a habilidade química de isolamento térmico e armazenamento de energia, as florestas se tornam meios naturais de armazenamento de energia (Huang, 2017; Coutinho, 2006).

A adoção das tecnologias próprias à Indústria 4.0 tem se tornado algo essencial no setor. As máquinas serão capazes de operar com maior flexibilidade e capacidade de utilização e com reação mais rápida dos processos aumentando a lucratividade e diminuindo a utilização de capital humano. A nível mundial, o setor planeja investir, em média, 4\% das receitas em digitalização e integração das operações. Em 2016, 38\% das empresas do setor possuíam alto grau de operação e $34 \%$ planejavam investimentos para adoção dessas tecnologias (PwC, 2016). Existem relevantes economias em matéria-prima, energia, produção e rendimento mediante a processos de otimização. Espera-se um aumento de $20 \%$ no tempo de vida de equipamentos, redução de $15 \%$ no consumo de energia e $20 \%$ em insumos, além de um aumento de 15\% da produção até 2035 (Martin, 2017).

\subsection{A Visão das Empresas Brasileiras}

Essa subseção se baseia em relatório de pesquisa de um dos autores (*******, 2018) do presente artigo. Para entender a realidade das empresas brasileiras quanto à adoção da Indústria 4.0 foram aplicados questionários (Anexo I), cuja amostra é formada por duas companhias de grande porte, sendo uma integrada desde a floresta ao papel e a outra focalizada nos segmentos florestal e de celulose(o que dificulta o cálculo da concentração de mercado). Porém, a título de ilustração, no momento em que os questionários foram respondidos, o valor de capitalização conjunto das duas empresas totalizava US\$ 40,1 bilhões, reforçando o grande porte das entrevistadas. Assim, as respostas refletem a percepção de tais empresas e, portanto, não são isentas de vieses.

O setor de P\&C é constituído por três etapas distintas em termos de características produtivas: floresta, celulose e papel. Nos segmentos industriais o desenvolvimento de inovações incrementais pode ocorrer em um período curto de meses, enquanto na atividade florestal a obtenção de resultados decorrentes a um novo produto ou processo delonga-se por décadas. Além disso, a escala produtividade e o grau de modernização são distintos nas três etapas, sendo o segmento de celulose o mais moderno tecnologicamente dado sua organização a nível global.

Para o segmento de celulose, a adoção de IoT não é maciça e sua difusão atual é considerada baixa/moderada, com expectativa de alta difusão até 2022 e adoção da tecnologia na rotina das pessoas e organizações. PIC apresenta iniciativas em países desenvolvidas, porém com baixa disseminação, especialmente em economias em desenvolvimento. Todavia, 
para o segmento florestal a difusão e o impacto já são considerados moderados. O cluster de IA e as tecnologias associadas têm presença pequena na indústria mundial frente às possibilidades vislumbradas, desta forma a análise de dados via big data é limitada.

As tecnologias de rede têm adoção moderada/alta, contudo a intensidade de adesão depende da região da planta produtiva, o que indica dificuldade para a adoção plena dadas as condições tecnológicas disponíveis em âmbito local. Além disso, as redes são normalmente utilizadas dentro de uma mesma linha produtiva, com pouca disseminação entre linhas de produção distintas. No segmento florestal, a tecnologia possui uma difusão baixa e um impacto moderada. É esperado que IoT, redes, PIC e IA possuam alta difusão no setor em 2027.

As biotecnologias têm difusão moderada no setor florestal e baixa no segmento industrial. Segundo as empresas consultadas, ainda que as fábricas de celulose sejam biorrefinarias, a ideia de extrair os produtos que possam contribuir para a sustentabilidade não são integralmente adotadas pelo setor. As tecnologias de edição de genomas para culturas vegetais representam grande importância para adoção do cluster no setor. Os materiais nanoestruturados possuem baixa difusão no setor, na medida em que a adoção dessa tecnologia impõe um alto investimento. Uma das barreiras para a adoção dessa tecnologia são as questões toxicológicas existentes em produtos nanoscópicos.

O cluster de materiais avançados se encontra em escala piloto no setor, com poucos projetos. Os compósitos são os principais representantes da tecnologia e possuem adoção e impacto reduzido. No entanto, é esperado que cheguem a um nível moderado até 2022. As tecnologias de armazenamento de energia apresentam baixo impacto, na medida em que as florestas são depósitos naturais de energia. A produção de celulose tem capacidade de geração de energia, o que representa uma vantagem para fábricas integradas de papel e celulose. Desta forma, esse cluster deve ter demorada adoção pelo setor. A Tabela 1 exprime a percepção predominante das empresas consultadas acerca da difusão clusters tecnológicos a nível mundial em 2017, 2022 e 2027. A Tabela 2 demonstra o grau de difusão e a intensidade do impacto em 2027.

Tabela 1: Percepção das empresas consultadas quanto à difusão dos clusters tecnológicos na indústria mundial de celulose - 2017, 2022 e 2027

\begin{tabular}{|c|c|c|c|}
\hline Tecnologias & $\mathbf{2 0 1 7}$ & $\mathbf{2 0 2 2}$ & $\mathbf{2 0 2 7}$ \\
\hline Internet das Coisas & Baixa/Moderada & Alta & Alta \\
\hline Produção inteligente e conectada & Baixa & Moderada & Alta \\
\hline Inteligência artificial, big data e computação em nuvem & Baixa & Moderada & Alta \\
\hline Redes de comunicação rápidas e seguras & Moderada/Alta & Alta & Alta \\
\hline Biotecnologia e Bioprocessos & Baixa/Moderada & Moderada & Alta \\
\hline Materiais nanoestruturados & Baixa & Moderada & Alta \\
\hline Materiais avançados & Baixa & Moderada & Alta \\
\hline Armazenamento de energia & Baixa & Baixa & Moderada/Alta \\
\hline
\end{tabular}

Fonte: Elaboração própria (2018). 
Tabela 2: Percepção das empresas consultadas quanto à difusão e intensidade do impacto dos clusters tecnológicos na indústria mundial de celulose -2027

\begin{tabular}{|c|c|c|}
\hline Teenologias & Difusão & Impacto \\
\hline Internet das Coisas & Alta & Moderado \\
\hline Produção inteligente e conectada & Alta & Alto \\
\hline Inteligência artificial, big data e computação em nuvem & Alta & Moderado \\
\hline Redes de comunicação rápidas e seguras & Alta & Alto \\
\hline Biotecnologia e Bioprocessos & Alta & Alto \\
\hline Materiais nanoestruturados & Alta & Alto \\
\hline Materiais avançados & Alta & Alto \\
\hline Armazenamento de energia & Moderada/Alta & Alto \\
\hline
\end{tabular}

Fonte: Elaboração própria (2018).

As vantagens do IoT estão ligadas a agilidade e redução dos custos de produção, além de melhoria da qualidade. IA, big data e computação em nuvem permitem a redução de custos em TI e ampliação da capacidade de análises complexas. O cluster de PIC permite uma produção rápida, automatizada e de alta qualidade, com operações logísticas automatizadas e otimizadas, e também a redução de custos. As tecnologias de rede proporcionam acessibilidade de informações de tempo real a um número maior de integrantes da cadeia produtiva. Além disso, esse cluster tem o poder de paralisar ou inviabilizar negócios ou países, de forma que as questões de segurança da informação são prioritárias para a indústria.

A biotecnologia propicia a redução de gases de efeito estufa e pegada de carbono, o enfoque do cluster é no segmento florestal dado a possibilidade de novos produtos sustentáveis. Assim, espera-se uma maior produção florestal e capacidade de adaptação a efeitos diretos de mudanças climáticas. A nanotecnologia permite novas aplicações e adoção de produtos de maior qualidade. Os materiais avançados servem como fonte de sustentabilidade e suprem a demanda de produtos de fontes verdes. $\mathrm{O}$ armazenamento de energia pode levar à reformulação dos padrões de concorrência e modelos de negócio ligados às fontes de energia não renováveis, por meio da redução de custos.

Dentro da amostra, não houve consenso quanto ao cluster tecnológico mais importante, de maneira que uma considera tecnologia de redes, materiais avançados, nanotecnologia e armazenamento de energia como mais relevante, enquanto a outra firma considera como prioritário PIC e biotecnologias.

Os obstáculos para adoção das tecnologias próprias à Indústria 4.0 são os investimentos para instalação de sensores e atualização da rede interna da unidade produtiva, especialmente para fábricas mais antigas, com mais de cinco anos de operação. Ademais, outros fatores são a segurança da informação, padronização de comunicação interna, disponibilidade de mão de obra especializada e fornecedores capazes de atender o aumento da demanda.

No âmbito dos clusters, as barreiras são mais específicas. Para tecnologias de rede o principal desafio são os ataques cibernéticos. PIC e IA possuem como empecilho a acessibilidade e aplicabilidade da tecnologia. Materiais avançados sofrem com a flutuação dos produtos da indústria de petróleo. Biotecnologias, nanotecnologias e armazenamento de energia enfrentam barreias regulatórias, sendo que o armazenamento de energia também possui a necessidade de alto investimento. No entanto, a intensidade dos benefícios são mais relevantes do que as barreiras, o que explica a elevada difusão dos clusters em 2027. 
O setor de P\&C brasileiro se aproxima das melhores práticas mundiais. No setor florestal, o país tem superioridade em relação aos competidores internacionais, ainda que as tecnologias de TIC ainda não sejam adotadas em sua plenitude. No segmento industrial, os fornecedores de equipamento e tecnologias são globalizados, de forma que novos investimentos são nivelados aos competidores internacionais. Individualmente, as firmas consultadas se colocam na fronteira tecnológica setorial. Uma delas destacou os próprios investimentos em IoT, big data, biomateriais e biocompósitos, nanocelulose e nanomateriais, biotecnologia arbórea e realidade aumentada e operação industrial e florestal autônoma. A outra companhia salientou investimentos em TIC de última geração.

\section{Considerações Finais}

Para o setor de P\&C, a Indústria 4.0 representa uma mudança complexa e dinâmica. As novas tecnologias permitirão o acesso a informações e facilitarão a tomada de decisões, por meio da conexão contínua e o uso de dados para o diagnóstico de máquinas, direcionamento da produção e otimização de custos. A digitalização do processo produtivo cria novos papéis e responsabilidades, ainda que diminuindo a interação humana direta em funções operacionais (Martin, 2017).

O investimento brasileiro se concentra no segmento de celulose considerando a cadeia de $\mathrm{P} \& \mathrm{C}$, dada a própria configuração industrial do país, de forma que o país tende consolidar sua atuação nesse segmento. O cenário do Brasil é de alta produtividade em relação aos competidores internacionais, com possibilidades de redução de custos. Os obstáculos mais significativos estão relacionados ao investimento de mão de obra, gestão, logística e segurança digital. Além disso, o setor tem um grande período de maturação das plantas industriais, levando muitos anos para que as inovações sejam adotadas na indústria (Rogers, 2018).

Os impactos da Indústria 4.0 não alteram radicalmente os modelos de negócio do setor, tendendo a reforçar estratégias competitivas dominantes (De Paula, 2018). Ademais, outros aspectos devem ser considerados, além daqueles tratados nesse artigo, tal como a influência dos mercados chinês e estadunidense, na medida em que ambos representam grande influência para o setor de P\&C.

As tecnologias da Indústria 4.0 permitirão o acesso à informação e facilitarão a tomada de decisões, as empresas mudarão a forma são que oferecidos o suporte e entrega de serviços aos clientes. Oportunidades de digitalização, integração e automação permitirão às empresas acrescentarem valor a si e a cadeia de valor. A importância da Indústria 4.0 aumenta à medida que as firmas procuram se manter relevantes na era da infraestrutura digital.

\section{Referências}

Aires, R. W. A., Moreira, F. K., \& Freire, P. S. (2017). Indústria 4.0: Desafios e Tendências para a Gestão do Conhecimento. SUCEG-Seminário de Universidade Corporativa e Escolas de Governo, 1(1), 224-247.

Andrade, P. S. A. D. M. (2017). A Quarta Revolução Industrial e sua Relação com a Produtividade Atual: Uma Revisão da Literatura. Monografia da Universidade de Brasília (UNB), Brasília/DF.

Berg, P., \& Lingqvist, O. (2017). Pulp, Paper, and Packaging in the next Decade: Transformational Change. McKinsey: Stockholm. 
Biazus, A., Hora, A. B. D., \& Leite, B. G. P. (2010). Panorama de Mercado: Celulose. BNDES Setorial, 32, 311-370.

BNDES. (2012). BNDES 60 anos: Perspectivas Setoriais. BNDES: Rio de Janeiro. Brussels.

CEPI. (2015).Paper Industry 4.0: What Digital can do for the Paper Industry. CEPI:

Conceição, O. A. C. (2000). A Centralidade do Conceito de Inovação Tecnológica no Processo de Mudança Estrutural. Ensaios FEE, 21(2), 58-76.

Correa, D. V. G. (2018). Celulose: Logística e Distribuição Internacional. SESI SENAI Editora.

Coutinho, J. (2006). Materiais de Mudança de Fase para Isolamento Térmico e Armazenamento de Energia. Engenharia Química, 2, 4-6.

De Paula, G. M. (2018). Nota Técnica do Sistema Produtivo Insumos Básicos e Foco Setorial Siderurgia. Relatório do Projeto Indústria 2027: Riscos e Oportunidades para o Brasil Diantede Inovações Disruptivas. IE-UFRJ: Rio de Janeiro; IE-UNICAMP: Campinas.

Fao. (2020). FAOSTAT-Forestry database. FAO: Rome.

Florêncio, M. N. S., Miranda, D. P. S. L., Santos, A. C., Dias, C. T., Russo, S. L., \& Oliveira Júnior, A. M. (2017). Prospecção Tecnológica: Um Estudo sobre os Depósitos de Patentes em Nanobiotecnologia. Cadernos de Prospecção, 10(2), 315. Doi: 10.9771/cp.v10i2.21453

Freitas, A. D. A. (2017). A Internet das Coisas e seus Efeitos na Indústria 4.0. Monografia da Universidade Federal Fluinense (UFF). Niterói/RJ.

Galindo-Rueda, F., \& Verger, F. (2016). OECD Taxonomy of Economic Activities Based on R\&D Intensity", OECD Science, Technology and Industry Working Papers, 2016/04, OECD Publishing, Paris. Doi: 10.1787/5jlv73sqqp8r-en.

GTAI (2014). Industrie 4.0: Smart Manufacturing for the Future. GTAI, Berlin.

Hermann, M., Pentek, T., \& Otto, B. (2016). Design Principles for Industrie 4.0 Scenarios. XLIXHawaii International Conference on System Sciences (HICSS), Koloa, 39283937. Doi: 10.1109/HICSS.2016.488.

Hora, A. B., Ribeiro, L. B. N. M., \& Mendes, R. (2018). Papel e Celulose = Paper and Cellulose. Visão 2035: Brasil, País Desenvolvido: Agendas Setoriais para Alcance da Meta, 119-142.

Huang, J. (2017). Sustainable Development of Green Paper Packaging. Environment and Pollution, 6(2), 1-7.

IBÁ (2020). Relatório 2019. IBÁ: São Paulo.

IEDI (2017). Indústria 4.0: A Quarta Revolução Industrial e os Desafios para a Indústria e para o Desenvolvimento Brasileiro. IEDI: Brasília.

IEL (2017). Mapa de Clusters Tecnológicos e Tecnologias Relevantes para Competitividade de Sistemas Produtivos. IEL/NC: Brasília. 
Jones, P., \& Comfort, D. (2017). The Forest, Paper and Packaging Industry and Sustainability. International Journal of Sales, Retailing and Marketing, 6(1), 3-21.

Karlović, I. (2017). Technologies for using Big Data in the Paper and Printing Industry. Journal Print Media Technology Research, 6(2), 75-84.

Laestadius, S. (1998). The Relevance of Science and Technology Indicators: The Case of Pulp and Paper. Research Policy, 27(4), 385-395. Doi: 10.1016/S0048-7333(98)00050-X

Martin, C. (2017). Indústria 4.0 Aponta Caminhos para Chegar à Fábrica do Futuro: Máquinas Inteligentes e Comunicação Entre Processos serão Novo Padrão dos Parques Fabris de Celulose e Papel. O Papel, 78(4).

Martins, N. F. S. (2018). Estudo das Vantagens da Aplicação de Metodologias, Indústria 4.0, no Contexto Industrial. Dissertação da ISEP, Porto. Paris.

OCDE (2017). OECD Science, Technology and Industry: Scoreboard 2007. OCDE:

Ojala, J., Lamberg, J. A., Peltoniemi, M., Särkkä, T., \& Voutilainen, M. (2013). A Evolução da Indústria de Papel Global. O Papel, 74(9).

Ojala, J., Voutilainen, M., \& Lamberg, J. A. (2012). The Evolution of the Global Paper Industry: Concluding Remarks. The Evolution of Global Paper Industry 1800 - 2050, 345-363.

Peixoto, J. A., \& Pereira, L. M. (2018). Industria 4.0 na Auto-Organização dos Sistemas Produtivos. Revista Eletrônica Científica Da UERGS, 4(3), 525-538. Doi: $10.21674 / 2448-0479.43 .525-538$

Perez, C. (2010). Technological Revolutions and Techno-Economic Paradigms. Cambridge Journal of Economics, 34(1), 185-202. Doi: 10.1093/cje/bep051

Pinho, M., \& Avellar, A. P. M. (2002). Economia de Escala, Barreiras à entrada e concentração na Indústria de Celulose e Papel. Encontro Nacional de Engenharia de Produção, 22, 1-8.

Piotto, Z. C. (2003). Eco-eficiência na indústria de celulose e papel-estudo de caso. Tese da Universidade de São Paulo (USP).

PwC. (2016). Industry 4.0: Building the Digital Enterprise. PwC: Munich.

Santi, T. (2018). Negócios e Mercado: Segurança Cibernética na Indústria 4.0. O Papel. 79(2), 59-60.

Santos, B. P.; Alberto, A.; Lima, T. D. F. M.; Charrua-Santos, F. M. B. (2018). Industry 4.0: Challenges and Opportunities, Revista Produção e Desenvolvimento, 4(1), 111124. Doi: $10.32358 /$ rpd.2018.v4.316

Schwab, K. (2019). A Quarta Revolução Industrial. Edipro: São Paulo.

Shaikh, F. K., Zeadally, S., \& Exposito, E. (2015). Enabling Technologies for Green Internet of Things. IEEE Systems Journal, 11(2), 983-994. Doi: 10.1109/JSYST.2015.2415194 


\section{ANEXO}

\section{Questionário I}

Este questionário tem como objetivo coletar informação a respeito da perspectiva das empresas de celulose a respeito da Indústria 4.0.Por favor, responda cada item com pequeno texto expositivo.

Nome da empresa:

Nome do entrevistado:

Telefone do entrevistado:

E-mail do entrevistado:

1. Qual é a intensidade da difusão das seguintes tecnologias na indústria mundial hoje?

1.1. Internet das coisas: sistemas, equipamentos e componentes

1.2. Tecnologias de redes de comunicação rápidas e seguras

1.3. Inteligência artificial, big data e computação em nuvem

1.4. Produção inteligente e conectada

1.5. Materiais avançados

1.6. Materiais nanoestruturados

1.7. Armazenamento de energia

1.8. Bioprocessos e biotecnologias avançadas

2. Qual é a intensidade da difusão das seguintes tecnologias na indústria mundial em 2022 ?

2.1. Internet das coisas: sistemas, equipamentos e componentes

2.2. Tecnologias de redes de comunicação rápidas e seguras

2.3. Inteligência artificial, big data e computação em nuvem

2.4. Produção inteligente e conectada

2.5. Materiais avançados

2.6. Materiais nanoestruturados

2.7. Armazenamento de energia

2.8. Bioprocessos e biotecnologias avançadas

3. Qual é a intensidade da difusão das seguintes tecnologias na indústria mundial em 2027 ?

3.1. Internet das coisas: sistemas, equipamentos e componentes

3.2. Tecnologias de redes de comunicação rápidas e seguras

3.3. Inteligência artificial, big data e computação em nuvem

3.4. Produção inteligente e conectada

3.5. Materiais avançados

3.6. Materiais nanoestruturados

3.7. Armazenamento de energia

3.8. Bioprocessos e biotecnologias avançadas

4. Quais são as tecnologias apontadas anteriormente possui maior impacto para o setor mundial em termos de estrutura der mercado, padrões de concorrência e modelos de negócios? Favor explicar quais são os impactos e sua racionalidade. 
5. Quais são os principais benefícios e as principais barreiras à adoção das oito tecnologias no setor mundial?

5.1. Principais benefícios

5.2. Principais barreiras

6. Como se situa a indústria brasileira frente aos melhores competidores internacionais em termos de geração e de difusão nas oito tecnologias apontadas?

7. Como se situa a sua empresa frente aos melhores competidores nacionais em termos de geração e de difusão nas oito tecnologias apontadas?

8. Quais são os principais desafios no âmbito nacional para aumentar a geração e difusão de tais tecnologias? As tecnologias desenvolvidas são facilmente adaptáveis ao Brasil?

9. Quais são os principais desafios no âmbito setorial para aumentar a geração e difusão de tais tecnologias?

10. Quais são os principais desafios no âmbito empresarial para aumentar a geração e difusão de tais tecnologias?

11. Quais são as principais recomendações de política? 